\title{
Chapter 10 \\ Biochar-Compost Mixtures as a Promising Solution to Organic Waste Management Within a Circular Holistic Approach
}

\author{
Federico Varalta and Jaana Sorvari
}

\begin{abstract}
In the common linear economy approach, organic waste treatment mainly generates energy, due to the existing demand and the goal of reducing the use of fossil fuel. Yet recent innovations and associated products are calling for an increasingly diverse use of organic waste within a circular holistic framework where the biochar and composting mixture appears to be the key to achieving a robust solution for sustainable development. Nonetheless, the inhomogeneity of organic waste and the synergies between biochar and composting require further investigation before broad-scale field application. In this chapter, we illustrate how governmental policies should be updated and revised to effectively support the development of new sustainable solutions, that should take into account social, economic and environmental implications, as well as their mutual interactions. As a consequence, robust tools and reliable procedures to evaluate sustainability will have to be established in this new ecological structure.
\end{abstract}

Keywords Organic waste - Waste management - Biochar-compost mixtures · Terra preta $\cdot$ Nutrients recycling $\cdot$ Circular economy $\cdot$ Sustainability

\section{Introduction}

Global population growth and the increased consumption of natural resources are placing an unprecedented pressure on already strained natural resources. To cope with increased food demand, human activities related to agriculture and food production have significantly altered nutrient cycles, depleted soils and increased greenhouse gas (GHG) emissions. Global population growth and the related food

F. Varalta $(\bowtie) \cdot$ J. Sorvari

Aalto University, Espoo, Finland

e-mail: federico.varalta@aalto.fi; jaana.sorvari@aalto.fi 
demand are straining the already fragile equilibrium of natural resources. The new sector of bioeconomy is seeking to reconcile the challenges of producing more food, while, at the same time, lowering the environmental burden. In this context, the proper management of organic waste can play a prominent role in tackling the mounting challenges. At the same time, current recycling and rebalancing actions have been insufficient to counter these adverse environmental consequences. Nutrients and organic matter have leaked without any control into the environment through food processing activities, excessive crop fertilising, poorly managed breeding of livestock and uncollected human waste (Kirschenmann 2010). The results of such anthropogenic pressure on natural resources have turned the ecosystem into a suffering status: with eutrophication of water bodies, air pollution and global warming. In addition, despite the higher food production capacity achieved, one person out of seven still has limited access to food and suffers from hunger. This, in turn, has exacerbated social discrimination and increased inequality (Foley et al. 2011). The concepts of bioeconomy (first) and circular economy (later) were developed to tackle these challenges, and to reduce the burden on natural resources. Many sectors of the economy are reassessing the way they operate, with the aim of achieving a sustainable mode of action. As a consequence, material flows in past years have been simplified and new methods have been developed for efficient reuse, or optimisation of the use, of natural resources. Fast-changing sectors of the global economy, such as energy production, have implemented circular economy, while more traditional segments, for example food production and agriculture, are still lagging (Buckwell and Nadeu 2016). Likewise, actions have been taken and the model of circular economy promoted across all sectors, fuelled also by updates in international and local legislation. To date, several governments and international organisations have developed programmes to improve the sustainability of human activities (European Commission 2012, 2018; The White House 2012), and governmental institutions have started to prompt policies to facilitate the shift towards circular economy. Educational organisations (Ellen Macarthur Foundation 2019; UN Food and Agriculture Organization (FAO) and RUAF Foundation 2015) are promoting research to overcome the deficit of circular economy in traditional sectors, and gradually new notions of bioeconomy are being shaped. Ultimately, bioeconomy offers the possibility to develop new sustainable processes that make it possible to secure the world's future food production demand while significantly reducing the environmental burden of related activities. Under these circumstances, the sustainable management of organic waste through efficient recycling of nutrients contained in that waste, increased carbon sequestration, and green energy production plays a prominent role.

In this chapter, the concept of a circular holistic approach to biowaste management is introduced. A critical comparison between the linear and the circular approach is presented, with a particular focus on the potential benefits of biocharcompost mixture (BCM) in the global context of bioeconomy.

In the long run, the aim is not only to preserve natural resources and to create an environmentally and economically sustainable future, but also to create a viable economy sector that will gradually replace obsolete courses of action and create 
new job opportunities. In other words, a complete shift of mindset is required in the implementation of bioeconomy, where traditional methods and treatment techniques are deemed no longer applicable and new ones must be developed. The circular holistic approach to organic waste management offers the opportunity to answer the new challenges. In particular, the development of techniques that efficiently return nutrients and organic matter back to the soil can be one of the keys to a new sustainable future.

\section{Organic Waste in a Linear Economy}

Despite the recent effort in terms of policies to promote the reuse and recycling of organic waste in different forms, the biowaste management sector still largely relies on a straightforward approach, with a linear progress (Fig. 10.1).

The linear approach consists mainly of applying the same treatment process to all available organic waste streams, regardless of their characteristics. Such an approach usually results in a main product with high profitability and a side product that, most of the time, has no-or negligible-commercial value. In commercial terms, the offered solution has the sole benefit of maximising the output quantity of a single product. Currently, this approach is preferred over more complex schemes because, in most cases, the end products already have an established market, with existing integrated logistics and an appropriate distribution network. In fact, these end products are typically drop-in commodities (Webster and Francis 2016), such as fuels or energy, with no need to develop new markets for alternative products. These linear processes are also robust and well established among the organic waste treatment industry, have become more reliable, do not pose any particular challenges in technical or operational terms, and are well framed in the environmental legislation.

Nevertheless, it is undeniable that the simplicity of the linear approach also represents its major drawback. As indicated by the 17 Sustainable Development Goals issued by the United Nations (United Nations 2018), sustainability is a complex subject that cannot be simplified to the implementation of one single, though important, target, in tackling global sustainability challenges. Aside from the social

Fig. 10.1 A typical linear process for organic waste treatment

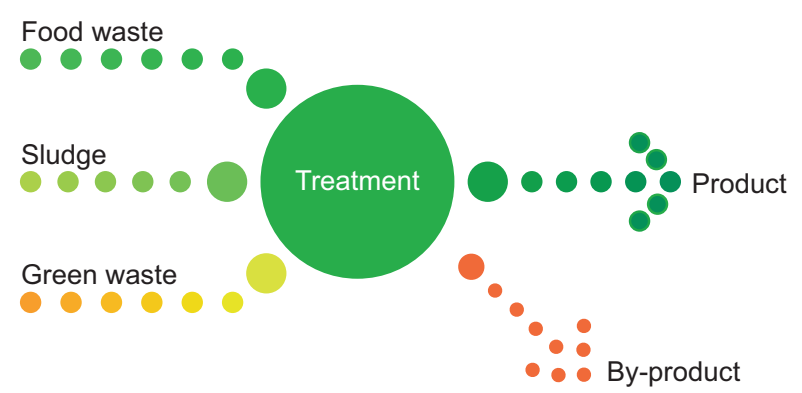


aspects of the sustainability goals, the integration of other environmental criteria besides carbon and water footprints are of paramount importance in order to secure the sustainability of recycling processes as well as the related value chains. More specifically, organic waste treatment processes should be evaluated also from the viewpoint of rebalancing the nutrients flows in ecosystems and the potential to sequestrate carbon in the soil.

\section{Novel Mode of Action Founded on Circularity}

The development of circular models and the associated public awareness of sustainability makes the linear approach obsolete. It is therefore necessary to elaborate new models that allow the full use of organic waste potential, and, at the same time, secure overall sustainability. A circular approach that takes into account the multifaced aspects of organic waste treatment, that is a holistic approach, offers the possibility to answer the mounting challenge by integrating new treatment technologies with more traditional processes (Fig. 10.2).

The holistic circular approach shares some traits with the industrial symbiosis concept, where a network of separate industries recovers and redirects resources and the by-products of its processes to improve the efficiency of the overall business. In the case of organic waste management, the holistic circular approach would suggest that we first treat the biological fraction of municipal solid waste (MSW) to produce, for example, animal feed through the cultivation of larvae insects. The remaining unused substrate could be combined with liquid organic waste from dairies in a wet biogas process and the digestate could then be combined with biochar produced from the pyrolysis of scrap wood or any other waste with a high content of lignin and composted to produce a soil amendment or an organic fertiliser. This type of approach is extremely flexible as it can be adapted to virtually any

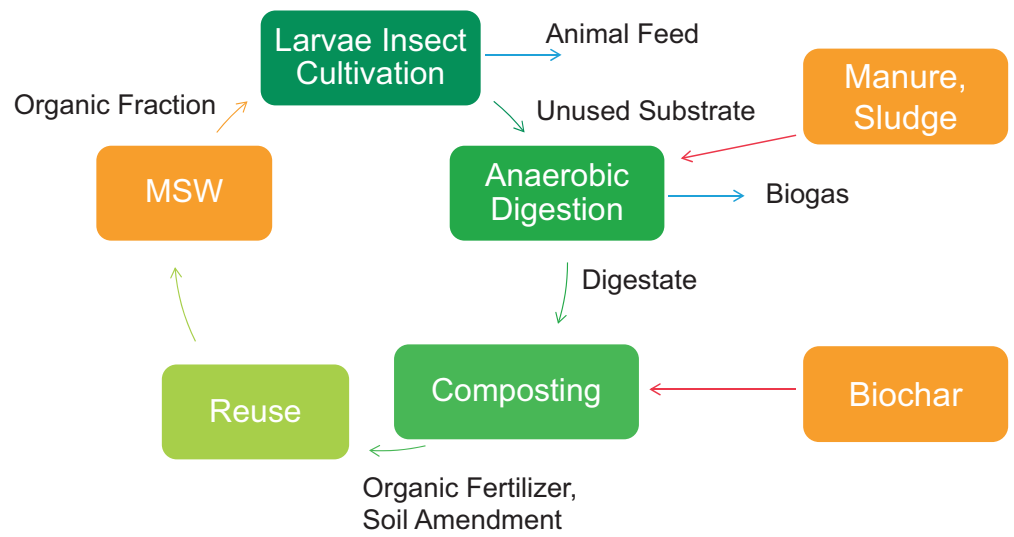

Fig. 10.2 Framework of a holistic circular approach to the management of organic waste 
conditions. In fact, there are several combinations of the processes for treating organic waste and the development of new applications increases the number of possibilities. The holistic methodology behind the circular approach allows for the introduction of the cascade organic waste treatment concept. This model originated in the paper industry, where higher value-added products are first extracted, and at the end of the product transformation cycle residues of the separate treatments are redirected to energy production processes (Keegan et al. 2013). For organic waste, the components with higher commercial value would be initially separated, while the residues or by-products from the process that generates the high-end products would form the basis for producing organic fertiliser. Through this theoretical model, the natural cycle of nutrients and organic matter might be completely closed.

The approach of circularity in organic waste management offers a number of advantages. Primarily, the heterogenous organic waste streams can be rationalised by directing them to the most suitable treatment process, reducing the risk of losing efficiency. The characterisation of organic waste is also an important factor for process efficiency implementation, as each treatment process is selected in accordance with the raw material characteristics. It thus becomes clear that this process chain can better tolerate higher variations in the organic waste quality and, consequently, larger fluctuations in the end products' market price. Such an approach no longer depends on the availability of a single feedstock or a few feedstocks, and it can be easily adjusted according to the local conditions. In addition, it enables quick adaptation in the event of changes in the demand of the products at the global level. A consequence of the higher process flexibility of the circular approach is the possibility of bridging the gap between the multiple sectors generating organic waste and creating a network where mutual added value is generated. In the past, the lack of integration of waste management process, the use of specialised technologies and the legislative issues of sectors like agriculture, sanitation, or MSW have led to a very fragmented and inefficient environment for by-product production (Buckwell and Nadeu 2016). The intrinsic flexibility of the holistic approach carries within itself the opportunity to further streamline the production processes of single operation by creating an additional recycling loop between the different sectors and consequently generating more added value.

In addition to the fact that the integration of different sectors contributes to improve efficiency of organic waste treatment, the recycling of nutrients is optimised, and nutrient losses are reduced (Sutton et al. 2013). Nevertheless, despite the recent improvement in managing organic waste streams, nutrients still leak into the environment (Fig. 10.3).

Contrary to the linear approach, the circular approach makes it possible to focus on nutrients reuse and recycling across the whole range of organic waste. The improved management of nutrients entails the identification of the proper actions for a specific nutrient and the selection of the most appropriate process in accordance with the final application.

The holistic circular approach offers the opportunity to improve carbon sequestration in soil. In particular, composting combined with biochar from the pyrolysis process enables the prospect of storing large quantities of carbon in soil as these 

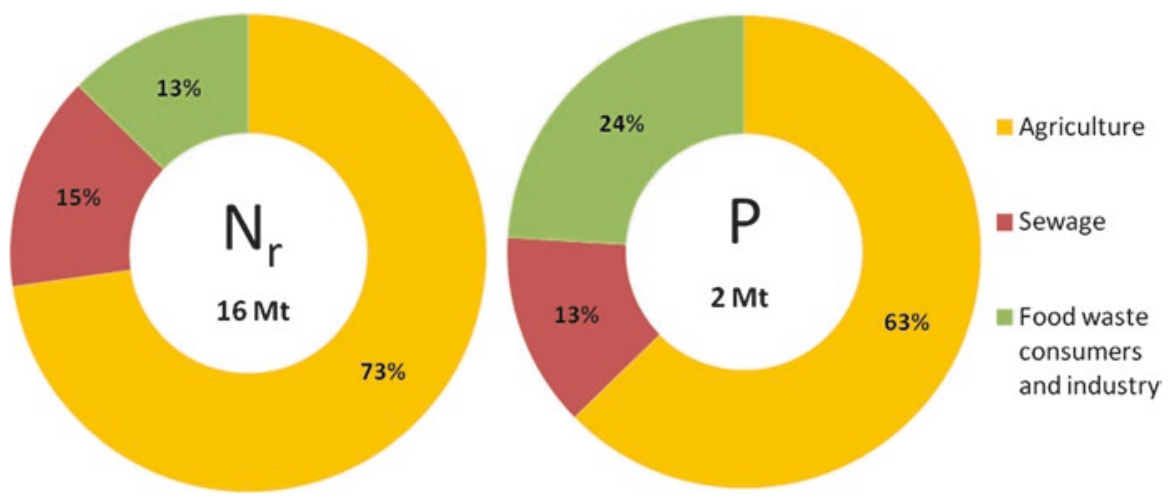

Fig. 10.3 Main nutrients leakage from EU countries. (Buckwell and Nadeu 2016)

techniques can treat problematic biomasses and by-products from other treatment processes that would otherwise remain unutilised (Fischer and Glaser 2012; Viaene et al. 2016). Notably, the proper management of soil organic matter in terms of carbon sequestration contributes directly to the better management of the nutrients as it is the largest reservoir of nutrients. Hence, practices that improve carbon sequestration in soil will probably also have a positive impact on the availability of nutrients (Fischer and Glaser 2012).

\subsection{Composting and Biochar: Synergism as a Support to the Holistic Approach}

In a circular holistic approach context, the final step (Fig. 10.2) plays a very important role. The effective management of the final residuals from different processes guarantees not only the profitability of the process in economic terms, but also enables sustainability for human-related activities - in particular, agriculture and food production. In fact, the current shift in agriculture practices towards selective farming and knowledge-intensive precision crops requires an efficient nutrients recycling system, coupled with environmentally friendly practices, in order to return organic matter to the soil.

In this context, the qualities of the Terra preta (dark earth) agro-ecosystem offers a model to optimise organic waste management within a circular holistic approach. In fact, Terra preta is a particular soil of anthropogenic origin found in irregular patches in the tropical rainforests of Amazonia, characterised by high concentration of nutrients and high stability of humified organic matter. Terra preta was produced by the incorporation of charred human waste, which is rich in nutrients, in soil (Glaser and Birk 2012), and different studies have demonstrated the key role of biochar in the formation of dark earths over the years. 
Biochar is obtained through pyrolysis by using organic waste as feedstock. Virtually any type of organic waste can be used as a raw material to produce biochar, although the type of feedstock significantly affects the properties of the produced biochar. According to the so-called 'charcoal vision' (Laird 2008), biomass processing through pyrolysis can be a sustainable approach for extracting energy from organic waste through their thermal transformation into bio-oil, syngas and charcoal. While the produced syngas can provide energy to the pyrolyser, the oil and charcoal fractions can be used too as secondary raw materials in various sectors. For example, the use of biochar as soils amendment can increase its physical, chemical and biological fertility, and represents a potential carbon sink because the estimated half-life of carbon in soil is more than 1000 years. Recently, biochar has gained renewed attention as a means to sequestrate carbon and, at the same time, improve soil quality (Tammeorg et al. 2014). It has already been observed that the direct application of biochar to the soil increases water retention capacity, total porosity, and soil mean temperature, and also improves the rate of ion exchange and retention of nutrients. An increased microbial activity has also been detected after the application of biochar in the soil (Gul et al. 2015), although the results from about a decade of experiments are not always consistent.

Even though biochar improves soil quality and the availability of nutrients, it does not provide soil with a sufficient amount of nutrients. The natural approach of combining biochar with compost instead produces a substrate rich in nutrients. The aim is, in the first place, to replicate the Terra preta process with the help of modern composting technologies and, successively, to produce an organic fertiliser or soil amendment as efficient as the current commercially available soil amendments and completely replace chemical fertilisers. In accordance with the circular holistic approach, the final target for biochar-compost use is thus the efficient management of available organic waste streams and a full exploitation of waste potential that generates sustainable added value in the existing production chains.

Nonetheless, the process of artificially recreating the Terra preta effect cannot be obtained by the simple combination of charred material and compost: It requires a deep understanding of the physico-chemical processes involved. The simple combination of charred material and compost does not result in the realisation of Terra preta. There may be many mechanisms that play a key role that have not yet been fully identified. In addition, the inhomogeneity of organic waste used is a challenge. The high variability in the quality of the raw material is not ideal for achieving a stable and reliable end product with a specific quality. Moreover, it should also be remembered that the aim is to employ the artificially produced Terra preta on soils that have different characteristics for various crops, and it cannot be excluded that artificial Terra preta with given characteristics may even produce contrasting results when applied on different soils.

In the next section, the initial promising findings of the interaction between biochar and composting are presented. The results from the land application of newly produced Terra preta are then separately evaluated. 


\subsection{Recent Developments in BCM}

Integration of biochar in compost to simulate the realisation of artificial Terra preta soils is still at the early stage, and therefore the results of recent studies are indicative, not definitive, regarding the potential that lies in the synergies between biochar and raw material processed by composting. It is thus premature to assess if BCM fulfils the 'end of waste' criteria introduced in the Waste Framework Directive (2008/98/EC). In fact, no common methodology exists for the application of biochar to compost. So far, it has been applied indistinctively both before and after the composting process. Here, we introduce the results from studies where biochar has been applied before or during the composting process, because these procedures increase the benefits of the combination. Moreover, these specific set-ups allow us to evaluate how the composting parameter modification impacts the quality and the characteristics of the mixture of compost and biochar.

One of the most important additional benefits of adding biochar before the composting process is the temperature increase during composting. This is an aspect of great importance within the circular holistic approach. In fact, higher temperatures also mean higher levels of hygienisation, and allow the use of feedstocks, such as municipal sewage sludge and animal manure. It seems that the increase of the temperature is caused by the fact that biochar is filling the gaps in between the composting mass, thereby reducing the overall heat loss of the system (Zhang et al. 2014). This has a direct impact on the thermophilic phase of the composting process. It is interesting to note, however, that in some cases the addition of biochar extends the duration of the thermophilic phase (Li et al. 2015; López-Cano et al. 2016), while in other cases, it reduces the duration itself (Awasthi et al. 2016b). Some contradictory outcomes are most probably due to the temperature of the pyrolysis and the type of feedstock employed in biochar production (Awasthi et al. 2016a).

The higher retention capacity of the biochar also has a positive effect on the composting process. Moisture is a key parameter of the composting process, in order to obtain a mature compost with stable organic matter. Researches have registered higher moisture contents in composting piles with biochar when compared piles without biochar ( $\mathrm{Li}$ et al. 2015). The higher moisture content in the pile consequently reduces the water losses and the leakage of nutrients (Theeba et al. 2012). Hence, biochar addition to the composting piles is indirectly responsible for more effective nutrient retention.

One of the main targets of the integration of the biochar and composting process is the increase of the content of nutrients and their bioavailability in the final product. While there is evidence of increased content of nutrients, the mechanisms involved are very complex and still not known in depth. Some studies have observed higher concentrations of $\mathrm{P}, \mathrm{K}, \mathrm{Ca}$ and $\mathrm{Mg}$ ions in the end product when biochar is added prior to the composting process (Zhang et al. 2014), when compared to end products without biochar, and this can be ascribed to the biochar's high ion exchange capacity. The negatively charged surface of the biochar has the ability to retain cations like $\mathrm{K}^{+}, \mathrm{Ca}^{2+}$ and $\mathrm{Mg}^{2+}$, through electrostatic attractions reducing the leaking 
during the composting process. On the other hand, the fate of phosphorus measured as phosphate $\left(\mathrm{PO}_{4}{ }^{3-}\right)$ after biochar addition is not clear. Zhang et al. (2014) have ended up with contradictory results, showing that addition of biochar increases the $\mathrm{PO}_{4}{ }^{3-}$ concentration in the end product when compared to the compost without addition, whereas during the process the total $\mathrm{PO}_{4}{ }^{3-}$ concentration decreased. This was explained by hypothesising that soluble $\mathrm{P}$ could be taken up by the microorganisms during the composting process. However, the influence of biochar addition to the $\mathrm{P}$ bioavailability seems to be a more complex issue than has previously been observed (Vandecasteele et al. 2016; Xu et al. 2013). The initial P content in the biochar itself appears to be an important factor in determining the bioavailability of phosphorus in soil. In addition, the $\mathrm{pH}$ value seems to be a key element in determining the concentration of $\mathrm{P}$ in compost, but its measurement is complicated due to the interactions with other mineral compounds. Other studies also suggest that timing of biochar addition to the composting process affects the final concentration (Vandecasteele et al. 2017). The lack of consistent data on P concentration in the compost after biochar addition deserves further research in order to better understand the mechanism involved.

The addition of biochar to the composting process has clear beneficial effects on other macronutrients than P. Earlier studies have shown that the addition of biochar reduces $\mathrm{N}$ losses, owing to the capacity of biochar to adsorb ammonia $\left(\mathrm{NH}_{4}{ }^{+}\right)$and ammonium $\left(\mathrm{NH}_{3}\right)$ (Hua et al. 2008). However, this is not the only mechanism triggered by biochar in connection to $\mathrm{N}_{2}$ emission reduction during the composting process. Lopez-Cano et al. (2016) reported that the addition of biochar to the composting process decreased the rate of the ammonification process. This result was explained by the fact that biochar creates a favourable environment for the growth of nitrifying bacteria, leading to the reduction of gaseous NOx emissions from the composting process, resulting in the double benefit of increasing the end product's value and reducing the GHG emissions in the atmosphere. This hypothesis is supported by the high porosity of the biochar added in the composting process, which improves the oxygen distribution in the matrix, making the aerobic microbiological processes more efficient (Sánchez-García et al. 2015).

Other researchers (Li et al. 2015; Malinska et al. 2014) have also emphasised an indirect benefit of biochar addition linked to the fact that biochar promotes microbial enzymatic activity that accelerates the degradation of organic matter. This specific outcome depends on the fact that biochar can adsorb molecules, such as $\mathrm{NH}_{3}$, $\mathrm{NH}_{4}{ }^{+}, \mathrm{H}_{2} \mathrm{~S}$ and $\mathrm{SO}_{4}{ }^{2}$, that slow down the organic matter degradation rate when present in excess as free ions in the composting matrix. Jindo et al. (2016) also observed that the addition of biochar to the composting process has a direct influence on the microbial community, by increasing bacterial biomass over fungal biomass over time. However, the study did not indicate any benefit, though the capacity to shift the microbial population might have attractive applications when dealing with difficult organic waste having a high organic load.

Biochar not only accelerates the degradation process, but also increases the stability of the organic matter in the soils by increasing the aromatic character of the mixture (Zhang et al. 2014). The addition of biochar to the composting matrix 
protects the humic substance against decay by adsorbing them (Jindo et al. 2016). Furthermore, biochar in the composting matrix improves the organic matter humification, especially reducing the fulvic acids fraction, which are recognised as the least stable.

An additional interesting characteristic of biochar is the ability to adsorb heavy metals (Inyang et al. 2016) and organic contaminants commonly found in sewage sludge. Many studies have confirmed the ability of biochar to reduce the availability of heavy metals in the compost from sewage sludge (Cui et al. 2016; Borchard et al. 2012; Chen et al. 2010). Sorption of heavy metals by biochar involves several mechanisms, which mainly depend on the structure of the biochar itself. This is probably also the reason why the feedstock for the biochar and its production method are major determinants affecting the bioavailability of heavy metals. Some bioavailability studies have documented divergent results. For example, Lopez-Cano et al. (2016) found that the addition of biochar to composting had no effects on the bioavailability of heavy metals. Related to land application, the effect of ageing of $\mathrm{BCM}$ on the bioavailability of contaminants is still unknown. In addition, only limited information is available on the effect of biochar on organic contaminants, and the underlying mechanisms. Oleszczuk et al. (2014) reported that the bioavailability of polycyclic aromatic hydrocarbons (PAH) was reduced in biochar-added composting sewage sludge. In the case of organic contaminants, biochar might also stimulate the development of microorganisms that can degrade them (Godlewska et al. 2017). However, more research is needed to identify the mechanisms of sorption and to understand how to increase the microbial population responsible for the degradation of the organic contaminants.

\subsection{Artificially Formed Terra Preta and Crop Growth}

The potential positive synergy between biochar and the composting process has been confirmed also at a practical level, though the number of studies on this topic is still limited. In particular, very interesting results have been reported in cases where a BCM has been applied on land to increase crop yield.

The application of BCM on ferralsols in Australia has increased the maize yield and plant growth in terms of grain production and leaves chlorophyll content and nutrients uptake (Agegnehu et al. 2016a). Results from the land application of BCM on Ethiopian fields cropped to barley also showed similar results (Agegnehu et al. 2016b), and paralleled earlier results on oat cultivated either in a greenhouse or in open fields in the tropics (Schulz et al. 2013). The BCM proved to be effective in terms of crop yield when compared to a separate, single application of biochar or compost, or a chemical fertiliser. Nevertheless, the research was not yet able to highlight the mechanisms behind the interaction between biochar and compost in the enhancement of plant growth. Another study revealed the potential of BCM to counteract stress caused by water deficit in the cultivation of cucumber in a 
controlled greenhouse environment (Nadeem et al. 2017). At the same time, the study confirmed the capacity of the mixture to improve plant growth and yield.

The results from trials conducted in temperate climate zones are not as promising as those realised in tropical areas. Schmidt et al. (2014) tested the use of BCM in a vineyard soil with low fertility over a period of 3 years. The application of the mixture did not have a positive effect on any of the parameters analysed and showed only a minor positive effect on plant growth of the first year that disappeared in time. The results from another study (Seehausen et al. 2017) revealed that the application of the mixture even had a negative effect on plant growth and the total leaf area of the plants. This research was conducted in a controlled environment and only with composted spent substrate from the cultivation of mushrooms. Therefore, the results are applicable only to a very limited selection of raw materials and cannot be generalised.

\section{Untapped Economic Potential of Organic Waste}

The simplification of the criteria to assess sustainability has also justified the implementation of costs analysis schemes that do not take into account economic variables that cannot be directly connected to investments or operational costs. The lack of comprehensive financial analysis has generated optimistic expectations that often do not match the real market situations. As a consequence, revenue schemes based on a linear technology approach are very sensitive to the variation of the gate fees generated from the different raw materials and their quality. This issue has been extensively studied: for example, in the case of biogas production technology (Boulamanti et al. 2013). In addition to the variability of gate fees, it must be noted that organic waste treatment plants are generally developed on a very local basis, while the products usually follow the prices of the global market. Therefore, the low output quantity cannot influence the demand and the corresponding market price (Philp et al. 2017). For these reasons, in a linear approach, a frequent practice is to compensate for the variability of the main sources of income by increasing the marketability of the by-products for applications permitted by environmental legislation, but which were not considered in the economic models. However, the sustainability of practices associated with the sale of by-products needs further investigation. As an example, in the economy of biogas plants, the sale of digestate, the main by-product, plays an important role in the overall economic profitability of the plant (Gebrezgabher et al. 2010). As a consequence, digestate is often marketed as a very efficient organic fertiliser, despite the fact that the sustainability of this practice is debatable as the benefit in terms of nutrients recycling efficiency is not evident. In fact, the characteristics of digestate might promote the formation of nitrous oxides, a potent GHG when applied to the soil (Nkoa 2013). Recent field studies have confirmed the hypothesis that the land application of digestate can increase the nitrous oxide emissions to above normal levels (Eickenscheidt et al. 2014; Fiedler et al. 2017). It must be noted that in several countries or regions, 
digestate application to soil is not even practicable. Similarly, composting technology in a linear approach is very dependent on gate fees and the sale of the end product. The presence of municipal sewage sludge, which is a feedstock that has a high gate fee, limits the use of the end product from composting due to negative public perceptions. On the other hand, the uncontrolled use of other feedstocks to improve the appeal of the end product can increase the GHG emissions, thereby weakening the sustainability of the process (Lim et al. 2016a, b). By contrast, the use of pyrolysis technology to produce biochar in a linear approach would appear to be economically viable and sustainable at the same time, although the economic viability is currently questionable since this technology needs to be improved and scaled up, particularly for feedstocks that are not derived from lignocellulosic biomass (Roy and Dias 2017). In addition, recent studies do not support the conclusion of a reduced carbon footprint related to biochar, and the current biogenic carbon retention models might lead to incomplete conclusions in terms of sustainability (Guest et al. 2013).

The shortcomings of the linear approach associated with the latest developments in the sector of organic waste treatment have led to recent calls for a more diverse use of organic waste in order to fully exploit this multipurpose resource. New treatment techniques have gained more attention as a means to diversify the use of organic waste, secure more stable revenues in the long term and to improve the sustainability of the treatment processes and the corresponding production chains. Among these techniques, extraction of acids from the biogas process, production of animal feed by breeding insects on organic waste substrate and cultivation of algae in wastewater are among the most promising. Despite their higher profitability, the reason for their minor application in comparison to the generation of biogas or compost products depends on the fact that producing these alternative end products normally requires a specific feedstock, and a deeper understanding of the process, in order to be viable.

\section{Barriers to the New, Holistic and Circular Approach}

In spite of the positive effect that a circular holistic approach could induce, its application is still limited to experimental studies or small-scale projects, as there are several technical, economic and legislative issues that still prevent the adoption of such a model on a larger scale.

\subsection{Lack of Innovative Supply Chains}

The development of a circular holistic approach, and the creation of synergies and mutual benefits between the different sectors involved, requires in many cases the establishment of new supply chains for the new products. The products from these 
recycling processes are not easily integrated into the existing production chains. They frequently require extensive evaluation before substituting the traditional raw materials in the industry without compromising the main production process itself. The application of new raw materials is thus very slow in the food processing industry and in agriculture sectors, which already operate in a very competitive environment. An additional hindrance is the prevailing reluctance to accept anything generated from organic waste. This reluctance arises from a lack of knowledge of the long-term consequences related to their use.

\subsection{Subsidising Policies}

However, the most significant factors slowing down the development of a holistic approach are governmental subsidies policies. While the aim of supporting policies is to boost the green economy, evidence shows that in most cases they work as a deterrent to innovation and the development of new markets (Carus et al. 2014). As a consequence, organic waste resources are not properly allocated and most of the potential is lost due to erroneous intervention. In fact, current policies that support the production of biofuels and bioenergy from organic waste effectively prevent the development of and investment in products with a higher market value, such as proteins or natural acids. These policies are mainly justified by the effort to reduce GHG emissions and secure energy supply (Keegan et al. 2013). However, they fail to address the importance of other organic waste-based products with a higher market value according to the cascading concept as they do not provide any mechanism that would promote their application on a wide basis. The contradictory outcome of policies supporting the use of organic waste as a source of energy is also evident in other aspects. Usually, these policies have a secondary target, namely the development of rural areas by supporting agriculture through the generation of alternative revenue streams. However, the outputs (biofuels and bioenergy) of the new agricultural activities are not so significant that it can influence the global market. At the same time, the price fluctuations of fossil fuels are often a challenge for the economics of the production on a rural level (Keegan et al. 2013). This creates a further increase of the problems in rural areas without capitalising on the potential of all organic waste available in agricultural activities.

\subsection{Non-holistic Policies}

Governmental policies have also contributed to the wide adoption of the linear approach, though that was probably not the intended objective. As a matter of fact, many governmental institutions have issued specific policies to improve sustainability practices, where the main focus is on the reduction of GHG emission. This, in turn, has favoured the application of processes where the benefit gained from the 
reduced carbon footprint is easily comparable against the emissions from the fossil raw material. The financial support provided by governments has then led to a situation where most often the only criterion applied to measure sustainability is the capability to reduce GHG emissions (Bosch et al. 2015). Further benefits for the circular economy may come from the harmonisation of environmental and agricultural legislation.

\section{Looking Ahead to the Future Development of BCM}

$\mathrm{BCM}$ clearly has the potential to offset the negative consequences of agriculture intensification and the larger amount of waste from the food industry by enhancing the management of nutrient recycling and providing stable soil organic matter. In addition, BCM fits seamlessly into the bioeconomy concept as it can utilise, through the holistic approach, by-products and materials that are formed in other organic waste treatment processes but that are not suitable as such for processing with the available treatment options. The flexibility in terms of input materials also makes it possible to solve any problems with feedstock availability by processing waste from different sectors, such as the food industry, agriculture or wastewater treatment. However, before the wide application of the circular holistic approach can take place, there are still some challenges to be solved. In addition to a lack of policies that promote nutrients recycling and the restoration of organic matter in the soil, there are still technical and environmental aspects that must be addressed in order to understand the impact of $\mathrm{BCM}$ on the ecosystem. As discussed above, several studies dealing with BCM have been conducted, but these studies lack a common and systematic approach that would make it possible to predict the precise quality of the end product based on the characteristics of the feedstock. Currently, the experimental results seem promising only for a few raw materials; they cannot be generalised.

In strictly operational terms, future studies should focus on the effect of biochar addition on the biomass prior to the composting process. Though the results from previous studies are not always consistent, this set-up seems to be the most promising since it allows us to study not only the benefits of the combination of biochar and compost but also the mechanisms that regulate the interactions of these materials during the composting process. As described above, the addition of biochar to the compost process improves the porosity of the material and increases the temperature ( $\mathrm{Li}$ et al. 2015; Theeba et al. 2012; Zhang et al. 2014). Conversely, it is likely that the modification of the operational parameters of composting, such as moisture or air feeding rate, affects the characteristics of the end products by changing the interactions between biochar and biomass during composting. Therefore, future studies should aim to identify how to adjust the process parameters in order to achieve the desired output irrespective of the feedstock.

The possibility to further research on the mechanisms involved in the interaction between biochar and compost will also help specify more accurately the 
characteristics of the mixture and narrow down the applications. At present, the different combinations of biochar and compost are usually applied indistinctively as soil amendments, organic fertilisers, and as a means to reduce persistent organic pollutants, without any assessment of the quality of feedstock or the contribution of process parameters. Despite the flexibility in being able to treat several types of organic waste, it is unlikely that one single combination of feedstock and process parameters can result in an end product that is optimal for all different applications. Future strategies should therefore focus on selecting suitable applications based on the local requirements and tailoring the process conditions in composting to produce end products with the desired characteristics. In this context, the characterisation of the feedstock emerges as an important factor in the optimisation of the efficiency in the selected application. In fact, the final use of the biochar and compost mixture restricts the selection of feedstock, as not all organic waste will be completely suitable for the selected process in terms of quality. As a consequence, mainly feedstock with the most suitable features will be processed. Unsuitable organic waste streams will either be processed to produce BCMs with different characteristics, or simply redirected to a more suitable treatment process within the holistic circular model for managing organic waste. This will further contribute to the increase of the overall material efficiency and streamline the management of organic waste streams towards sustainable development.

The technological developments need to be accompanied by novel approaches to measuring the degree of sustainability of BCM and its use. As one of the targets of $\mathrm{BCM}$ is to properly manage the nutrients cycle, it is logical to introduce new means to evaluate the potential to reuse nutrients. There are some techniques available to analyse the flow of nutrients in the natural cycle. While these techniques lack the ability to evaluate the efficiency of the recycling processes in qualitative terms, Grönman et al. (2016) proposed an approach that would take into account the efficiency of reusing nutrients in relation to their available amount. This novel method to calculate the 'nutrient footprint' offers the potential to help understand which processes and applications can increase the efficiency of reusing nutrients in various production chains. The degree of sustainability of the BCM can be further studied by integrating life cycle assessment and risk analysis. Life cycle assessment and risk analysis focus on other environmental aspects, such as carbon sequestration, eutrophication, soil acidification and contamination, associated with the recycling and reuse of organic waste in agriculture, which is both the initial generator and the final user of the end products in the holistic, circular approach to managing organic waste (Oldfield et al. 2018). In particular, the integration of parameters (e.g. carbon sequestration, eutrophication and soil acidification) that indicate the health of soil is of paramount importance to ensure sustainable development (Oldfield et al. 2018). As a matter of fact, soil depletion is one of the major threats to sustainable agriculture (Pimentel et al. 1995), but a circular holistic approach, by proper management of nutrients and constant replacement of organic matter in the top soil, can reverse the current adverse trends. It must be noted, however, that new means to assess sustainability require further validation before an extensive adoption. In fact, these new tools have been tested on a very limited range of specific conditions and only with 
one single crop or food chain. It is also clear that the sustainability of the circular holistic approach should be supported by economic and social considerations. However, the integration of such aspects might be difficult at a general level.

\section{Conclusions}

The circular holistic approach based on composting as a core treatment method offers a new model to cope with the mounting food demand by exploiting in full the potential of organic waste resources and, consequently, reducing the burden on the environment by combining existing and new treatment technologies. In particular, the synergies between biochar and compost offers the opportunity to improve the sustainability of the management of organic waste through efficient reuse of nutrients and return of the organic matter back to the soil. This new approach needs to be further supported not only by a deeper understanding of the mechanisms involved that cause the positive synergism of biochar and compost, but also by appropriate methods for sustainability assessment and encouraging policies. Common guidelines for the production of mixtures of biochar and compost should be developed in parallel with instruments that measure the sustainability with a broad scope. These new instruments should include tools to evaluate not only the reduction in GHG emissions but also other environmental parameters, the focus being on the efficiency in recycling nutrients and carbon sequestration of soil. Correspondingly, the possibility to quantify the sustainability of the new approach presented in this chapter will make it possible to revise the current environmental policies in order to promote sustainability as a whole, and not only from a narrow viewpoint.

\section{References}

Agegnehu, G., Bass, A. M., Nelson, P. N., \& Bird, M. (2016a). Benefits of biochar, compost and biochar/compost for soil quality, maize yield and greenhouse gas emissions in a tropical agricultural soil. Science of the Total Environment, 543, 295-306.

Agegnehu, G., Nelson, P. N., \& Bird, M. I. (2016b). The effects of biochar, compost and their mixture and nitrogen fertilizer on yield and nitrogen use efficiency of barley grown on a Nitisol in the highlands of Ethiopia. Science of the Total Environment, 569-570, 869-879.

Awasthi, M. K., Wang, Q., Huang, H., Li, R., Shen, F., Lahori, A. H., Wang, P., Guo, D., Guo, Z., Jiang, S., \& Zhang, Z. (2016a). Effect of biochar amendment on greenhouse gas emission and bio-availability of heavy metals during sewage sludge co-composting. Journal of Clean Production, 135, 829-835.

Awasthi, M. K., Wang, Q., Ren, X., Zhao, J., Huang, H., Awasthi, S. K., Lahori, A. H., Li, R., Zhou, L., \& Zhang, Z. (2016b). Role of biochar amendment in mitigation of nitrogen loss and greenhouse gas emission during sewage sludge composting. Bioresource Technology, 219, 270-280.

Borchard, N., Prost, K., Kautz, T., Moeller, A., \& Siemens, J. (2012). Sorption of copper (II) and sulphate to different biochars before and after composting with farmyard manure. European Journal of Soil Science, 63, 399-409. 
Bosch, R., Van De Pol, M., \& Philp, J. (2015). Define biomass sustainability. Nature, 523, 526-527.

Boulamanti, A. K., Maglio, S. D., Giuntoli, J., \& Agostini, A. (2013). Influence of different practices on biogas sustainability. Biomass and Bioenergy, 53, 149-161.

Buckwell, A., \& Nadeu, E. (2016). Nutrient recover and reuse (NRR) in European agriculture. A review of the issues, opportunities, and actions. Brussels: RISE Foundation.

Carus, M., Dammer, L., Hermann, A., \& Essel, R. (2014). Proposals for a reform of the Renewable Energy Directive to a Renewable Energy and Materials Directive (REMD). Going to the next level: Integration of bio-based chemicals and materials in the incentive scheme. Nova paper on biobased economy 2014-05, Nova-Institüt, Huerth, Germany.

Chen, Y. X., Huang, X. D., Han, Z. Y., Huang, X., Hu, B., Shi, D. Z., \& Wu, W. X. (2010). Effects of bamboo charcoal and bamboo vinegar on nitrogen conservation and heavy metals immobility during pig manure composting. Chemosphere, 78, 1177-1181.

Cui, E., Wu, Y., Zuo, Y., \& Chen, H. (2016). Effect of different biochars on antibiotic resistance genes and bacterial community during chicken manure composting. Bioresource Technology, 203, 11-17.

Eickenscheidt, T., Freibauer, A., Heinichen, J., Augustin, J., \& Drösler, M. (2014). Short-term effects of biogas digestate and cattle slurry application on greenhouse gas emissions affected by $\mathrm{N}$ availability from grasslands on drained fen peatlands and associated organic soils. Biogeosciences, 11, 6187-6207.

Ellen Mac Arthur Foundation. (2019). Approach: We inspire and enable the transition to a circular economy. https://www.ellenmacarthurfoundation.org/our-work/approach. Accessed June 2019.

European Commission. (2012). Innovating for sustainable growth: A bioeconomy for Europe. Communication from the Commission to the European Parliament, the Council, the European Economic and Social Committee and the Committees of the Regions, European Commission, B-1049 Brussels, Belgium.

European Commission. (2018). A sustainable bioeconomy for Europe: Strengthening the connection between economy, society and the environment: Updated Bioeconomy Strategy. Directorate-General for Research and Innovation Unit F, RTD BIOECONOMY COMMUNICATION, European Commission, B-1049 Brussels, Belgium. pp. 107, PDF. https:// doi.org/10.2777/792130. https://ec.europa.eu/research/bioeconomy/pdf/ec_bioeconomy_strategy_2018.pdf\#view=fit\&pagemode=none. Viewed June 2019.

FAO and RUAF Foundation. (2015). A vision for city region food systems - building sustainable and resilient city regions.

Fiedler, S. R., Augustin, J., Wrage-Mönnig, N., Jurasinski, G., Gusovius, B., \& Glatzel, S. (2017). Potential short-term losses of $\mathrm{N} 2 \mathrm{O}$ and $\mathrm{N} 2$ from high concentrations of biogas digestate in arable soils. The Soil, 3, 161-176.

Fischer, D., \& Glaser, B. (2012). Synergisms between compost and biochar for sustainable soil amelioration. In S. Kumar \& A. Barthi (Eds.), Management of organic waste (pp. 167-199). Rijeka: InTech.

Foley, J. A., Ramankutty, N., Brauman, K. A., Cassidy, E. S., Gerber, J. S., Johnston, M., Mueller, N. D., O'Connell, C., Ray, D. K., West, P. C., Balzer, C., Bennett, E. M., Carpenter, S. R., Hill, J., Monfreda, C., Polasky, S., Rockström, J., Sheehan, J., Siebert, S., \& Tilman, D. (2011). Solutions for a cultivated planet. Nature, 478, 337-342.

Gebrezgabher, S. A., Meuwissen, M. P., Prins, B. A., \& Lansink, A. G. O. (2010). Economic analysis of anaerobic digestion - A case of green power biogas plant in The Netherlands. NJASWageningen Journal of Life Sciences, 57(2), 109-115.

Glaser, B., \& Birk, J. J. (2012). State of the scientific knowledge on properties and genesis of anthropogenic dark earths in Central Amazonia [terra preta de indio]. Geochimica et Cosmochimica Acta, 82, 39-51.

Godlewska, P., Schmidt, H. P., Ok, Y. S., \& Oleszczuk, P. (2017). Biochar for composting improvement and contaminants reduction. A review. Bioresource Technology, 246, 193-202. 
Grönman, K., Ypyä, J., Virtanen, Y., Kurppa, S., Soukka, R., Seuri, P., Finér, A., \& Linnanen, L. (2016). Nutrient footprint as a tool to evaluate the nutrient balance of a food chain. Journal of Cleaner Production, 112, 2429-2440.

Guest, G., Bright, R. M., Cherubini, F., \& Strømman, A. H. (2013). Consistent quantification of climate impacts due to biogenic carbon storage across a range of bio-product systems. Environmental Impact Assessment Reviews, 43, 21-30.

Gul, S., Whalen, J. K., Thomas, B. W., Sachdeva, V., \& Deng, H. (2015). Physico-chemical properties and microbial responses in biochar-amended soils: Mechanisms and future directions. Agriculture Ecosystems and Environment, 206, 46-59.

Hua, L., Wu, W., Liu, Y., McBride, M. B., \& Chen, Y. (2008). Reduction of nitrogen loss and Cu and $\mathrm{Zn}$ mobility during sludge composting with bamboo charcoal amendment. Environmental Science and Pollution Research, 16, 1-9.

Inyang, M. I., Gao, B., Yao, Y., Xue, Y., Zimmerman, A., Mosa, A., Pullammanappallil, P., Ok, Y. S., \& Cao, X. (2016). A review of biochar as a low-cost adsorbent for aqueous heavy metal removal. Critical Reviews in Environmental Science and Technology, 46, 406-433.

Jindo, K., Sonoki, T., Matsumoto, K., Canellas, L., Roig, A., \& Sanchez-Monedero, M. A. (2016). Influence of biochar addition on the humic substances of composting manures. Waste Management, 49, 545-552.

Keegan, D., Kretschmer, B., Elbersen, B., \& Panoutsou, C. (2013). Cascading use: A systematic approach to biomass beyond the energy sector. Biofuels, Bioproducts and Biorefining, 7, 193-206.

Kirschenmann, F. (2010). Alternative agriculture in an energy- and resource-depleting future. Renewable Agriculture and Food Systems, 25, 85-89.

Laird, D. A. (2008). The charcoal vision: A win-win-win scenario for simultaneously producing bioenergy, permanently sequestering carbon, while improving soil and water quality. Agronomy Journal, 100, 178-181.

Li, R., Wang, Q., Zhang, Z., Zhang, G., Li, Z., Wang, L., \& Zheng, J. (2015). Nutrient transformation during aerobic composting of pig manure with biochar prepared at different temperatures. Environmental Technology, 36, 815-826.

Lim, S. L., Lee, L. H., \& Wu, T. Y. (2016a). Sustainability of using composting and vermicomposting technologies for organic solid waste biotransformation: Recent overview, greenhouse gases emissions and economic analysis. Journal of Clean Production, 111, 262-278.

Lim, S. L., Lee, L. H., \& Wu, T. Y. (2016b). Sustainability of using composting and vermicomposting technologies for organic solid waste biotransformation: Recent overview, greenhouse gases emissions and economic analysis. Journal Clean Production, 111, 262-278.

López-Cano, I., Roig, A., Cayuela, M. L., Alburquerque, J. A., \& Sánchez-Monedero, M. A. (2016). Biochar improves $\mathrm{N}$ cycling during composting of olive mill wastes and sheep manure. Waste Management, 49, 553-559.

Malinska, K., Zabochnicka-Świątek, M., \& Dach, J. (2014). Effects of biochar amendment on ammonia emission during composting of sewage sludge. Ecological Engineering, 71, 474-478.

Nadeem, S., Imran, M., Naveed, M., Khan, M., Ahmad, M., Zahird, Z., \& Crowleyb, D. (2017). Synergistic use of biochar, compost and plant growth-promoting rhizobacteria for enhancing cucumber growth under water deficit conditions. Journal of the Science of Food and Agriculture, 97, 5139-5145.

Nkoa, R. (2013). Agricultural benefits and environmental risks of soil fertilization with anaerobic digestates: A review. Agronomy for Sustainable Development, 34, 473-492.

Oldfield, T., Sikirica, N., Mondini, C., Lopez, G., Kuikman, P., \& Holden, N. (2018). Biochar, compost and biochar-compost blend as options to recover nutrients and sequester carbon. Journal of Environmental Management, 218, 465-476.

Oleszczuk, P., Zielińska, A., \& Cornelissen, G. (2014). Stabilization of sewage sludge by different biochars towards reducing freely dissolved polycyclic aromatic hydrocarbons (PAHs) content. Bioresource Technology, 156, 139-145. 
Philp, J., Schieb, A., \& Chelly, M. (2017). Understanding value chains in industrial biotechnology. Annales des Mines - Réalités industrielles, 1, 56-65.

Pimentel, D., Harvey, C., Resosudarmo, P., Sinclair, K., Kurz, D., Mcnair, M., Crist, S., Shpritz, L., Fitton, L., Saffouri, R., \& Blair, R. (1995). Environmental and economic costs of soil erosion and conservation benefits. Science, 267, 1117-1123.

Roy, P., \& Dias, G. (2017). Prospects for pyrolysis technologies in the bioenergy sector: A review. Renewable and Sustainable Energy Review, 77, 59-69.

Sánchez-García, M., Alburquerque, J. A., Sánchez-Monedero, M. A., Roig, A., \& Cayuela, M. L. (2015). Biochar accelerates organic matter degradation and enhances $\mathrm{N}$ mineralization during composting of poultry manure without a relevant impact on gas emissions. Bioresource Technology, 192, 272-279.

Schmidt, H. P., Kammann, C., Niggli, C., Evangelou, M. W. H., Mackie, K. A., \& Abiven, S. (2014). Biochar and biochar-compost as soil amendments to a vineyard soil: Influences on plant growth, nutrient uptake, plant health and grape quality. Agriculture, Ecosystems and Environment, 15, 117-123.

Schulz, H., Dunst, G., \& Glaser, B. (2013). Positive effects of composted biochar on plant growth and soil fertility. Agronomy for Sustainable Development, 33, 814-827.

Seehausen, M. L., Gale, N. V., Dranga, S., Hudson, V., Liu, N., Michener, J., Thurston, E., Williams, C., Smith, S. M., \& Thomas, S. C. (2017). Is there a positive synergistic effect of biochar and compost soil amendments on plant growth and physiological performance? Agronomy, 7.

Sutton, M. A., Bleeker, A., Howard, C. M., Bekunda, M., Grizzetti, B., de Vries, W., van Grinsven, H. J. M., Abrol, Y. P., Adhya, T. K., Billen, G., Davidson, E. A, Datta, A., Diaz, R., Erisman, J. W., Liu, X. J., Oenema, O., Palm, C., Raghuram, N., Reis, S., Scholz, R. W., Sims, T., Westhoek, H., and Zhang, F. S., with contributions from Ayyappan, S., Bouwman, A. F., Bustamante, M., Fowler, D., Galloway, J. N., Gavito, M. E., Garnier, J., Greenwood, S., Hellums, D. T., Holland, M., Hoysall, C., Jaramillo, V. J., Klimont, Z., Ometto, J. P., Pathak, H., Plocq Fichelet, V., Powlson, D., Ramakrishna, K., Roy, A., Sanders, K., Sharma, C., Singh, B., Singh, U., Yan, X. Y., \& Zhang, Y. (2013). Our Nutrient World: The challenge to produce more food and energy with less pollution. Global Overview of nutrient management. Centre for Ecology and Hydrology, Edinburgh on behalf of the Global Partnership on Nutrient Management and the International Nitrogen Initiative.

Tammeorg, P., Simojoki, A., Mäkelä, P., Stoddard, F. L., Alakukku, L., \& ja Helenius, J. (2014). Biochar application to a fertile sandy clay loam in boreal conditions: Effects on soil properties and yield formation of wheat, turnip rape and faba bean. Plant and Soil, 374(1-2), 89-107.

The Waste Framework Directive. (2008/98/EC). (2008). On waste and repealing certain Directives. Official Journal of the European Union, L 312/3.

The White House. (2012). National Bioeconomy Blueprint, 44.

Theeba, M., Bachmann, R. T., Illani, Z. I., Zulkefli, M., Husni, M. H. A., Samsuri, A. W., \& Samsuri, W. (2012). Characterization of local mill rice husk charcoal and its effect on compost properties. Malaysian Journal of Soil Science, 16, 89-102.

United Nations. (2018). About the sustainable development goals. https://www.un.org/sustainabledevelopment/sustainable-development-goals. Accessed June 2019.

Vandecasteele, B., Sinicco, T., D’Hose, T., Vanden Nest, T., \& Mondini, C. (2016). Biochar amendment before or after composting affects compost quality and $\mathrm{N}$ losses, but not $\mathrm{P}$ plant uptake. Journal of Environmental Management, 168, 200-209.

Vandecasteele, B., Willekens, K., Steel, H., D’Hose, T., Waes, C., \& Bert, W. (2017). Feedstock mixture composition as key factor for $\mathrm{C} / \mathrm{P}$ ratio and phosphorus availability in composts: Role of biodegradation potential, biochar amendment and calcium content. Waste and Biomass Valorization, 8, 2553-2567.

Viaene, J., Van Lancker, J., Vandecasteele, B., Willekens, K., Bijttebier, J., Ruysschaert, G., De Neve, S., \& Reubens, B. (2016). Opportunities and barriers to on-farm composting and compost application: A case study from northwestern Europe. Waste Management, 48, 181-192. 
Webster, P., \& Francis, R. (2016). Green shoots of success. Drivers and approaches towards a successful bioeconomy. The Chemical Engineering, 900, 24-28.

Xu, G., Wei, L. L., Sun, J. N., Shao, H. B., \& Chang, S. X. (2013). What is more important for enhancing nutrient bioavailability with biochar application into a sandy soil: Direct or indirect mechanism? Ecological Engineering, 52, 119-124.

Zhang, J., Lü, F., Shao, L., \& He, P. (2014). The use of biochar-amended composting to improve the humification and degradation of sewage sludge. Bioresource Technology, 168, 252-258.

The opinions expressed in this chapter are those of the author(s) and do not necessarily reflect the views of the United Nations University Institute for Integrated Management of Material Fluxes and of Resources (UNU-FLORES), its Board of Directors, or the countries they represent.

Open Access This chapter is licensed under the terms of the Creative Commons Attribution 3.0 IGO license (https://creativecommons.org/licenses/by/3.0/igo/), which permits use, sharing, adaptation, distribution and reproduction in any medium or format, as long as you give appropriate credit to the United Nations University Institute for Integrated Management of Material Fluxes and of Resources (UNU-FLORES), provide a link to the Creative Commons license and indicate if changes were made.

Any dispute related to the use of the works of the United Nations University Institute for Integrated Management of Material Fluxes and of Resources (UNU-FLORES) that cannot be settled amicably shall be submitted to arbitration pursuant to the UNCITRAL rules. The use of the United Nations University Institute for Integrated Management of Material Fluxes and of Resources (UNU-FLORES)'s name for any purpose other than for attribution, and the use of the United Nations University Institute for Integrated Management of Material Fluxes and of Resources (UNU-FLORES)'s logo, shall be subject to a separate written license agreement between the United Nations University Institute for Integrated Management of Material Fluxes and of Resources (UNU-FLORES) and the user and is not authorized as part of this CC-IGO license. Note that the link provided above includes additional terms and conditions of the license.

The images or other third party material in this chapter are included in the chapter's Creative Commons license, unless indicated otherwise in a credit line to the material. If material is not included in the chapter's Creative Commons license and your intended use is not permitted by statutory regulation or exceeds the permitted use, you will need to obtain permission directly from the copyright holder.

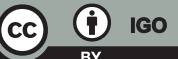

